\title{
Quantification of Raindrop Kinetic Energy for Improved Prediction of Splash-Dispersed Pathogens
}

\author{
D. J. Lovell, S. R. Parker, P. Van Peteghem, D. A.Webb, and S. J. Welham
}

First and third authors: IACR-Long Ashton Research Station, Department of Agricultural Sciences, University of Bristol, Long Ashton, North Somerset BS41 9AF, United Kingdom; second author: ADAS High Mowthorpe, Duggleby, Malton, North Yorkshire YO17 8BP, United Kingdom; fourth author: Silsoe Research Institute, Wrest Park, Silsoe, Bedford MK45 4HS, United Kingdom; and fifth author: IACR-Rothamsted, Harpenden, Hertfordshire, AL5 2JQ, United Kingdom. Accepted for publication 18 January 2002.

\begin{abstract}
Lovell, D. J., Parker, S. R., Van Peteghem, P., Webb, D. A., and Welham, S. J. 2002. Quantification of raindrop kinetic energy for improved prediction of splash-dispersed pathogens. Phytopathology 92:497-503.

An electronic sensor, based on a piezoelectric transducer, was tested in the laboratory using simulated raindrops, and in natural rainfall. Data were also collected for splash dispersal using tracer dyes in laboratory experiments and the Long Ashton splashmeter in field experiments. Droplets impacting on sensor produce sound waves that are detected by an omnidirectional microphone sealed within an acoustic chamber. An electrical charge, proportional to the sound wave, is produced by the microphone and is converted to a categorical scale and then stored to provide an accumulation of impacts over a specified period of time. Calibra-
\end{abstract}

ABSTRACT tion of the sensor was done using single-droplet impacts of known mass and impacting velocity. A linear relationship was shown between the categorical scale and the kinetic energy of impacting droplets (adjusted $r^{2}=0.99$ ). The best relationship fitted between splash dispersal from dye cup, and kinetic energy was a second-order polynomial (adjusted $r^{2}>$ 0.99). Splash height, recorded by the Long Ashton splashmeter during 41 natural rainfall events, was correlated closely with sensor output (adjusted $r^{2}=0.87$ ). Our studies indicate that the sensor provides quantitative data which could be incorporated into disease management systems to provide estimates of inoculum dispersal gradients within crop canopies.

Additional keywords: environmental epidemiology, meteorology, quantitative epidemiology, Septoria tritici, spore dispersal.
Splash-dispersed fungal and bacterial pathogens cause damage in a wide range of crop systems $(2,6,14,25)$. A tactic assumption of many predictive disease models is that splash height and rainfall intensity are related (7). However, Shaw (23) demonstrated that splash height could not be predicted from rainfall volume rate. This may explain why empirical relationships between disease and rainfall have generally provided levels of predictive precision that are inappropriate for decision making. In Western Europe, leaf blotch, caused by Septoria tritici, is the most serious foliar pathogen of winter wheat (19). Considerable yield loss can be caused if it becomes severe on the flag and second leaves $(24,25)$. Due to the unusually long latency of the pathogen, the distance between new leaves and sources of inoculum on basal leaves can be large during stem extension (22). Thus, vertical spore dispersal is often required to facilitate infection of the upper canopy leaves. Shaw (23) developed a forecast system which used a simple and inexpensive rain-monitoring device, the Long Ashton (LA) splashmeter, to estimate the potential for vertical spore dispersal during rainfall. An important assumption of this system is that inoculum is located on basal leaves. Recommendation of fungicide treatment is dependent on thresholds of splash height (where 6 drops of approximate size $>2 \mathrm{~mm}$ recorded above the threshold height constituted a splash event), which are defined for key growth stages of cereals. This system was effective in reducing recommended fungicide inputs and, compared with prophylactic systems, often led to improved economic control. However, the LA splashmeter system does not provide adequate prediction of disease risk for all crops (16). Furthermore, the information pro-

Corresponding author: D. J. Lovell; E-mail address: Darren.lovell@bbsrc.ac.uk

Publication no. P-2002-0215-01R

(C) 2002 The American Phytopathological Society vided was of a qualitative nature and, due to the visual detection method, does not allow remote operation. Theoretical models of splash dispersal within crop canopies suggest that the distance between inoculum and healthy leaves is crucially important in determining the risk of disease progress (29). However, such models generally assume that the inoculum is confined to a single region within the crop. Lovell et al. (11) demonstrated that this assumption is false for wheat crops infected by $S$. tritici because factors such as canopy architecture, rates of stem extension, and leaf expansion affect the position of inoculum in the crop. Methods of monitoring inoculum location have been developed (12) that enable quantitative prediction of the rain splash necessary to transport inoculum upwards as the crop develops. Although this system could enhance the predictive value of the LA splashmeter, it would more appropriately be used in conjunction with a device capable of quantifying both rain-splash height and amount. Such devices should preferably quantify, either directly or through association, information relating to individual rain drop kinetic energy. Several systems have the capability of providing such information (e.g., streak imaging [5], light scattering detection [26], and raindrop impact detection [10]). However, they often make short periodic but exhaustive measurements (up to 40 Mbytes/s), require extensive post-collection data manipulation, are expensive, and require skilful maintenance or are not robust or reliable enough to provide the high quality of data required. Madden et al. (15) described a rainfall kinetic energy sensor for continuous, remote measurement of rainfall properties (energy flux density) which can be used to infer total rainfall kinetic energy on a temporal scale (i.e., rainfall power). However, it does not record the energy of individual droplet impacts; therefore, information of rain type (e.g., shower, thunderstorm), rainfall rate (millimeter per hour), or drop-size spectrum may be an additional requirement to enable the prediction of probable spore dispersal. 
This article evaluates an electronic precipitation impact (PI) sensor, based on the piezoelectric transducer system reported by Joss and Waldvogel (10). The sensor provides information relating to individual droplet impacts and, thus, is not reliant on the determination of additional rainfall properties (e.g., rain type) to enable estimates of probable splash dispersal heights. Relationships are presented between PI sensor measurements and (i) splash dispersal obtained from single droplet releases in still air and (ii) splash height as recorded by the LA splashmeter in ambient U.K. rainfall. Examples of how PI sensor data might be incorporated into a decision support system are discussed.

\section{MATERIALS AND METHODS}

PI sensor. The sensor used in this study was manufactured by Aardware Design (Walton-on-Thames, UK; PI sensor sole distribution via AgMET, Tetbury, Glos, UK). The sensor electronics are hermetically sealed in an acoustic chamber, (dimensions: $95 \mathrm{~mm}$ wide by $95 \mathrm{~mm}$ deep by $55 \mathrm{~mm}$ high, weight $275 \mathrm{~g}$ ) with an upward-facing diaphragm. Air pressure pulses, produced by rainfall impacting on the diaphragm, are measured within the chamber by an omnidirectional microphone. The microphone converts the air pressure pulse into an electrical signal. A background noise filter, with a sample period of $25 \mathrm{~ms}$, is incorporated into the circuitry to reduce signal corruption by ambient noise. The sensor requires a $12-\mathrm{V}$ DC power supply with a typical current of $5 \mathrm{~mA}$. Electrical pulses, produced in response to raindrop impacts, are monitored continuously by the sensor. The amplitude of any pulse detected is held in short-term memory storage for the duration of the sample period. If more than one pulse is detected within a sample period, only the peak amplitude is retained. The amplitude is discriminated into one of 14 storage bins and registered on an associated counter. This process is repeated, allowing counters to build an aggregate profile of rainfall against time. Data from the 14 counters are logged at user-defined intervals (log periods), adjustable from $5 \mathrm{~min}$ to $24 \mathrm{~h}$. The counters for each storage bin can register between 0 and 255; additional impacts within the log period are ignored. After each log period, data are sent to long-term storage and counters are reset.

Uniformity of response over sensor surface. The response to droplets impacting on the sensor was tested for both symmetry and uniformity, using droplets of various sizes released from a height of $8.4 \mathrm{~m}$. Four equidistant circles with diameters of 1, 3, 5, and $7 \mathrm{~cm}$ were drawn, centered on the middle of the sensor to discriminate five zones. The response to 10 droplets of each size

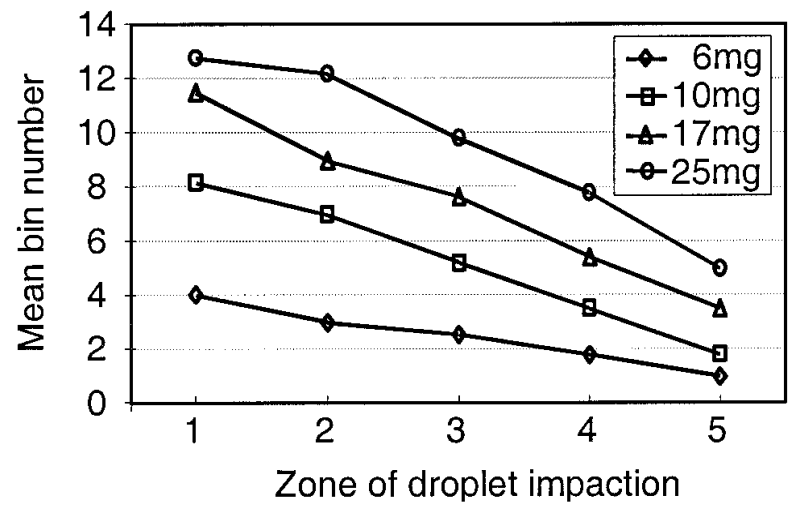

Fig. 1. Relationship between the position of droplet impaction (zone) on the precipitation impact sensor surface and the mean recorded output bin number for a range of drop sizes, calculated by average mass (mg) released from a height of $8.4 \mathrm{~m}$. Zones were defined by four concentric circles centered in the middle of the sensor with diameters of $1,3,5$, and $7 \mathrm{~cm}$. Zone 1 was defined as the area within the $1-\mathrm{cm}$ circle and zone 5 was defined as the area outside of the $7-\mathrm{cm}$ circle. was recorded for impacts within each of the zones. After each droplet impact, the sensor's surface was dried before releasing the next drop; this aided identification of the zone of droplet impact and ensured identical surface properties for all droplet impacts.

Sensor calibration. Water droplets of approximate diameters (calculated by average mass based on a unit density) 2.3, 2.7, 3.2, 3.6 , and $4.4 \mathrm{~mm}(6,10,17,25$, and $44 \mathrm{mg}$, respectively) were released, each from a range of heights to produce a wide range of droplet kinetic energy. In total, 87 combinations of mass and height were used, providing a kinetic energy range of 0.017 to $1.44 \mathrm{~mJ}$. Kinetic energy of droplets (kinetic energy of the droplet prior to moment of impaction) was estimated as a function of droplet mass and velocity $\left(\mathrm{KE}=1 / 2 \mathrm{mV}^{2}\right)$. Calculating the instantaneous velocity of the droplet requires calculation of the drag force on the droplet. However, droplets with diameters greater than $1 \mathrm{~mm}$ become deformed in flight so that their shape becomes uncertain. This uncertain shape means that either approximate relations (20) or complex numerical integration (31) are required for exact calculation of the drag force on the droplet. In order to avoid this problem, we used a simple model where the drag force on the droplet was assumed to be proportional to the square of the instantaneous velocity of the droplet. Droplet fall velocity profiles calculated using this simple model approximate well to those calculated using the more complex empirical model presented by Wang and Pruppacher (31). Our simple model gives velocity as a function of fall distance:

$$
V^{2}=V_{t}^{2}\left[1-\exp \left(-2 g s / V_{t}^{2}\right)\right]
$$

where $V_{t}$ is droplet terminal velocity and $g$ is acceleration due to gravity.

Terminal velocity was calculated using the equations presented by Reynolds et al. (21):

$$
V_{t}=88\left(1-\exp \left\{-[(d+0.115) / 1.718]^{1.336}\right\}\right)
$$

where $d$ is the droplet diameter in millimeters.

For each drop size-height combination, 25 measurements were taken for impacts on the central zone of the sensor. In order to avoid the introduction of errors due to differences in surface properties at the point of impaction, the sensor's surface was dried using an absorbent tissue following each droplet impaction. The time between droplet releases was approximately $5 \mathrm{~s}$.

Effect of impaction angle. The effect of droplet impaction angle on bin number was tested to simulate the effect of wind on natural falling raindrops. The sensor was tilted to a range of angles between 0 and $70^{\circ}$ (producing droplet impacts of between 90 and $20^{\circ}$ to the sensor's surface), and single droplets of 6 and

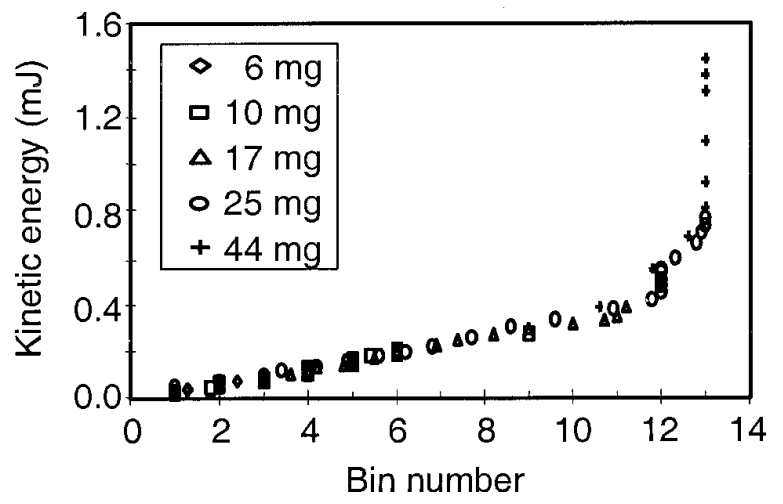

Fig. 2. Relationship between kinetic energy of impacting droplets and mean precipitation impact sensor output for a range of droplet sizes, calculated by average mass (mg) and release heights providing 87 different impact energies. Kinetic energy was calculated based on the mass and velocity of droplets. 
$25 \mathrm{mg}$ were released from a range of heights onto the central zone of the sensor

Effect of wind on recorded splash height and PI sensor droplet classification. Two LA splashmeters were positioned $10 \mathrm{~m}$ apart on an exposed site. A wind shelter ( $4 \mathrm{~m}$ wide by $4 \mathrm{~m}$ deep by $1 \mathrm{~m}$ high), constructed of Rokolene 1730 (Growing Technologies, Castle Donnington, UK), was positioned around one of the splashmeters. The screen effectively reduced near-ground wind speed and, therefore, reduced the probability of any affect of wind speed on the trajectory of splash droplets and consequently the position where they would be recorded on the splashmeter receptor paper. Reductions in wind speed of approximately $80 \%$, (N. M. Western, unpublished data) are typically achieved using this shelter method. The advantage of using a permeable material in such experiments is to reduce the possible effects of turbulent airflow and wind shear, which may have considerable affect on droplet fall properties. Data were collected from 25 natural rainfall events occurring between 25 September and 3 November 1998. In accordance with splashmeter operation procedures (23), the splashmeter was checked each morning and the dye paper changed if traces of dye were visible or if rainfall had occurred during the preceding $24 \mathrm{~h}$. Dye reservoirs were toped up if necessary.

Relationship between kinetic energy and splash height for LA splashmeter. Water droplets (calculated by average mass based on a unit density of water) of approximate diameters 2.3, $2.4,3.2,3.3,3.6,4.1$, and $4.4 \mathrm{~mm}(6.7,7.5,16.8,19.2,25,35$, and $44 \mathrm{mg}$, respectively) were produced using hypodermic needles of various sizes. The needles were connected to a perfusion pump, with variable flow rates of 0.6 to $600 \mathrm{ml} / \mathrm{h}$, to produce a constant flow of droplets at the rate of approximately 1 per $5 \mathrm{~s}$. Velocities at impact were estimated (using our simple model) as approximately $7.02,7.15,7.91,8.01,8.18,8.34$, and $8.43 \mathrm{~m} / \mathrm{s}$, respectively, for a fall distance of $12.9 \mathrm{~m}$, representing a value of $>98 \%$ of terminal velocity (21). For each size, 100 droplets were released from a height of $12.9 \mathrm{~m}$ onto a dye-filled cup as used on the LA splashmeter (23). Splash droplets, produced from the droplet impacts, were collected on a sheet of absorbent paper, $92 \mathrm{~cm}$ wide and $60 \mathrm{~cm}$ high, placed at right angles to the dye cup. This was centered vertically at a distance of $10 \mathrm{~cm}$ so that the entire sheet was exposed to splash droplets with different horizontal trajectory lengths as described by Walklate et al. (30). A separate sheet was used for each drop size and the dye cup was refilled when the sheets were changed.

Comparison of precipitation impact sensor and LA splashmeter. A standard LA splashmeter and a PI sensor, both positioned within the meteorological site at IACR-Long Ashton Research Station, were exposed to 41 natural rainfall events between 28 September 1998 and 13 March 1999. Splashmeters were operated

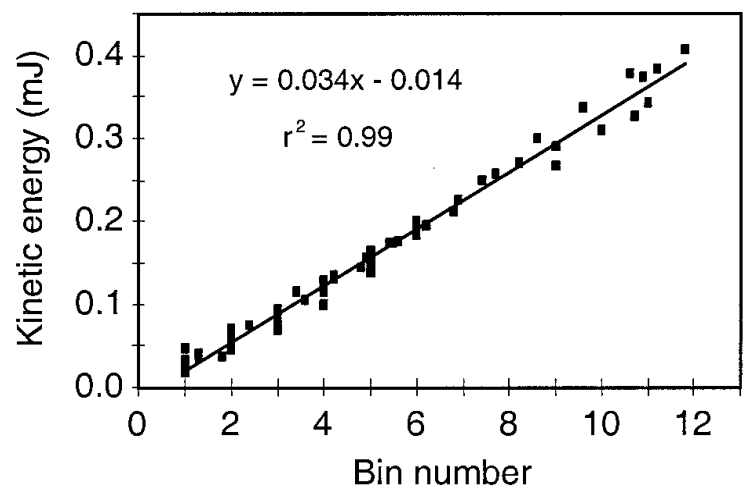

Fig. 3. Relationship between kinetic energy of impacting droplets and mean precipitation impact sensor output for impacts with a bin number allocation $<12$. The fitted line is a linear regression, equation show, with coefficient of determination for the fit represented as $r^{2}$. in accordance with standard operating procedures (23). Dye reservoirs were topped up if necessary. PI sensor data were collected whenever the splashmeter dye paper was changed. The heights of the six highest splash droplets with an approximate diameter $\geq 2.0 \mathrm{~mm}$ (23) on each of the dye papers was recorded to provide estimates of rain-splash heights. Estimates of splash heights were compared to PI sensor data using linear regression.

Effect of sample period and target area. The sample period of the impact sensor determines the frequency at which the maximum amplitude values, resulting from individual droplet impacts, are recorded. The probability that more than 1 droplet will impact on the sensors surface increases proportionally with increase in sample period; therefore, information on the number of impacts may be lost if the sample period is too long. However, too short a period results in the storage of unnecessary data (i.e., the storage of nil values), thus wasting memory space in the logger. Two custom-designed PI sensors, manufactured with a dual in-line switch to allow user-selectable sample periods, were operated next to a standard commercial PI sensor in natural rainfall. Sample periods of $1,2,10,15$, and $20 \mathrm{~s}$ were examined and comparisons made with the fixed 5-s sample period of the standard sensor.

Shields manufactured from 1.5-mm-thick aluminum, with circular apertures of 3 and $5 \mathrm{~cm}$ in diameter, were fitted to PI sensors to reduce the target area of impacting droplets. The shields were mounted at $2 \mathrm{~mm}$ above the sensor and droplets falling on the shield were not recorded by the instrument. The size of the target area determines the probability of raindrop impaction for a given sample period. Furthermore, if sensor nonuniformity occurs, then precision of detection may be impaired. Therefore, target area may have a significant effect on the performance of the sensor. Comparisons of data output were made for PI sensors, fitted with different shield sizes, operated next to each other in natural rainfall.

\section{RESULTS}

Uniformity of response over sensors surface. The position of droplet impaction had a significant effect on sensor output, with the bin number decreasing as droplets impacted within zones further from the center of the sensor (Fig. 1). For impacts within the linear range (i.e., > bin 12), a possible model to describe the relationship between observed impact $\left(N_{i}\right)$ and zone of impaction $\left(D_{i}\right)$ is the negative exponential curve, given as

$$
N_{i}=M_{i} \exp \left(-k D_{i}\right)
$$

where $M_{i}$ is the response of a droplet of a given size in the central zone. This model has the property that negative $N_{i}$ s cannot be

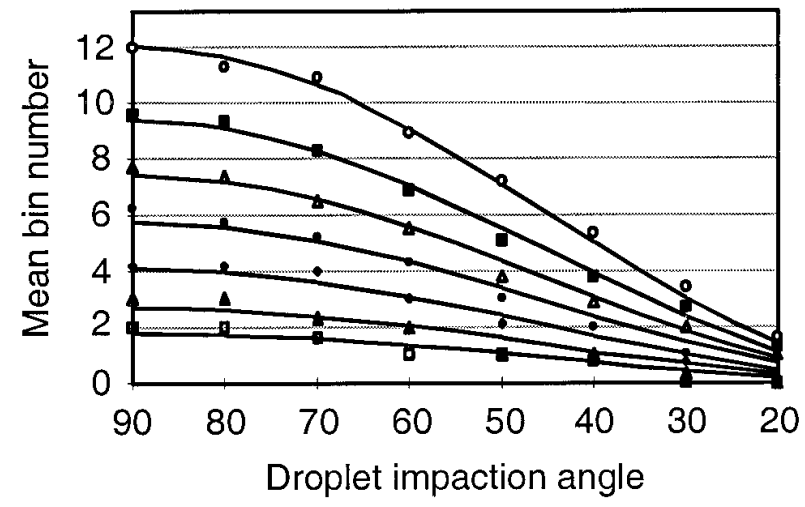

Fig. 4. Relationship between mean bin number recorded by precipitation impact sensor and angle of droplet impaction, where $90^{\circ}$ is at right angles to the sensors surface, for a range of drop size-release height combinations (depicted by symbols). Fitted curves represent equation (5). 
predicted, as could occur with a linear model versus zone. This model is equivalent to

$$
\ln \left(N_{i}\right)=\ln \left(M_{i}\right)-k D_{i}
$$

and was fitted using linear regression (adjusted $r^{2}=0.96$ ). There was no evidence that $k$ varied with differing $M_{i}$, so that the rate of decay with increasing distance from the center is independent of drop size.

Sensor calibration. The range of droplet energies created by variation in droplet size and release heights provided a broad spread of PI sensor output response; however, none of the droplets tested achieved bin 14 (Fig. 2). The relationship between sensor output (mean bin number classification) and kinetic energy of impacting drops was linear in the range bin 1 to 12 , with a coefficient of determination of the fit (adjusted $r^{2}$ ) of 0.99 (Fig. 3).

Effect of impaction angle. A decrease in sensor output value (bin number) was observed with increasing angle $(\theta)$ from the horizontal for all drop size-release heights. Drops normally impact on the sensor from a vertical trajectory of $90^{\circ}$ except when, for example, affected by wind. The velocities of droplets used in this experiment were calculated for the vertical plane (vertical velocity) (i.e., in a plane at right angles $\left[90^{\circ}\right]$ to the earth's surface). However, as the impact sensor was tilted to an angle $(\theta)$ away from the horizontal, the velocity of the impacting droplet in a plane at $90^{\circ}$ to the sensor's surface will be reduced to a proportion $\cos (\theta)$ of the vertical velocity Hence, the component of

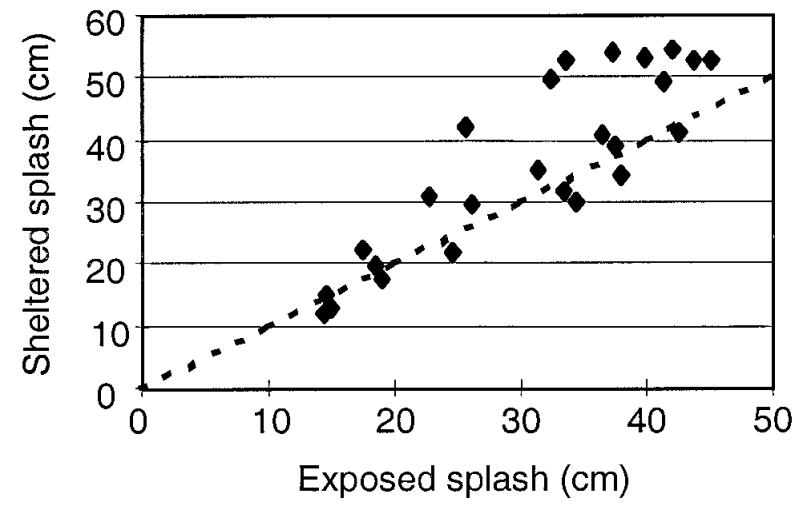

Fig. 5. Comparison of splash heights (mean of six highest splashes) recorded by two splashmeters, one positioned within a wind shelter the other exposed to ambient wind speed, during 25 natural rainfall events. The dashed line shows the line of equivalence.

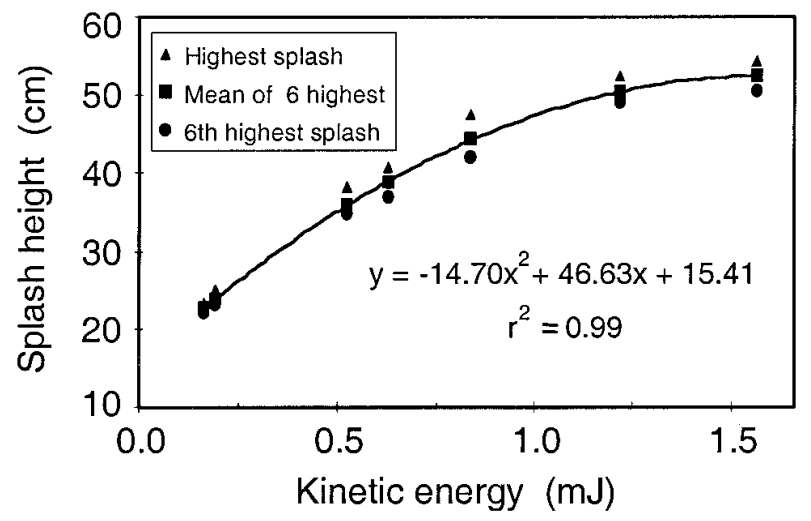

Fig. 6. Relationship between recorded splash height and kinetic energy of simulated raindrops at terminal velocity in still air. The fitted curve is a second-order polynomial, equation shown, with coefficient of determination for the fit represented as $r^{2}$. kinetic energy at right angles to the surface of the sensor will be proportional to $\cos ^{2}(\theta)$. Thus, the kinetic energy recorded by the sensor $\left(N_{i}\right)$ is given by

$$
N_{i}=M_{i} \cos ^{2}(\theta)
$$

where $M_{i}$ is the predicted vertical kinetic energy. To validate this model, a best-fit equation was fitted by regressing $N_{i}$ on $\cos ^{2}(\theta)$ with no intercept, which estimated $M_{i}$ for each drop size-release height combination using separate slopes (Fig. 4). The observed coefficient of determination (adjusted $r^{2}$ ) was greater than 0.99 , indicating that the model is a good description of the system.

Effect of wind. Dye papers taken from the two splashmeters, exposed to 25 natural rainfall events, were compared for both area of dye coverage and recorded height of splash droplets. Dye coverage on the exposed splashmeter was often concentrated on the windward side of dye papers. In contrast, dye coverage of papers taken from the sheltered splashmeter was more evenly distributed on a horizontal plane. The height of splash recorded by the sheltered splashmeter was often higher than that of the exposed splashmeter (Fig. 5). These differences were generally greatest for heavy rainfall and coincided with records where the dye was unevenly distributed on the splash paper.

Relationship between splash height and kinetic energy. A strong relationship was observed between the height of dye splash recorded on the receptor paper for droplets traveling at near terminal velocity $(>98 \%)$ in still air. A second-order polynomial explained $>99 \%$ of the variation in splash height, estimated as the mean of the six highest splash drops recorded on the receptor paper and the kinetic energy of impacting droplets (Fig. 6).

Maximum recorded splash height (highest splash droplet $\geq 2 \mathrm{~mm}$ ) recorded on the dye papers exposed to ambient rainfall correlated well (adjusted $r^{2}=0.87$ ) with the highest impact recorded by the PI sensor for the corresponding rain event (Fig. 7). However, considerable variation in splash height was observed for heavy rainfall, when impacts were recorded in the uppermost bins. This was due largely to the nonlinear response of the sensor within the upper bin range.

The energy spectrum of raindrops within three separate rainfalls was estimated from data recorded by the PI sensor. These rainfalls differed in amount and splash height as follows: event 1, 26 January 1999, $7.6 \mathrm{~mm}$ of rainfall and a maximum splash height of $45 \mathrm{~cm}$; event 2, 9 June 1998, $2.9 \mathrm{~mm}$ of rainfall and a maximum splash height of $48 \mathrm{~cm}$; and event 3, 7 October 1998, $2.8 \mathrm{~mm}$ of rainfall and a maximum splash height of $26 \mathrm{~cm}$.

Although all three rainfall events produced a similar number of impacts within the bin 1 range, distributions of raindrop kinetic

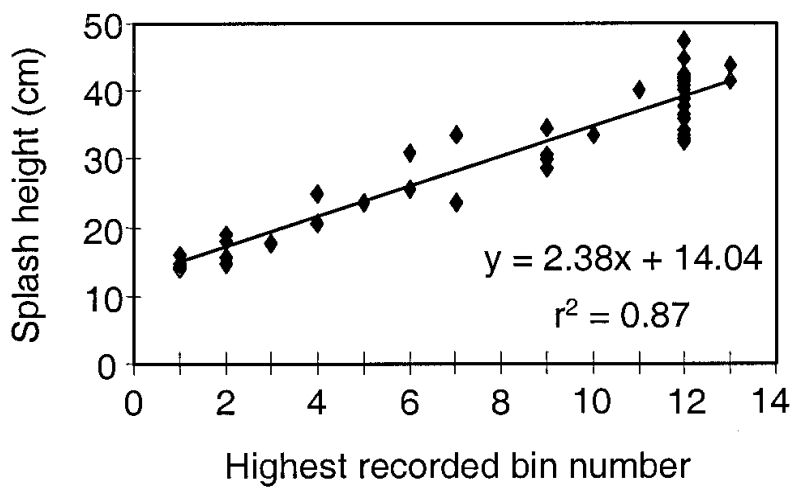

Fig. 7. Relationship between the maximum height of splash recorded by the LA Splashmeter and the highest impact recorded by precipitation impact sensor for 41 natural rainfall events at Long Ashton research station between 28 September 1998 and 13 March 1999. The fitted line is a linear regression, equation shown, with coefficient of determination for the fit represented as $r^{2}$. 
energy differed (Fig. 8). Rainfall event 2 provided a similar amount of rainfall as event 3 but both the number and energy content of impacting droplets was greater for event 2 . This is consistent with the large difference in the recorded splash heights for these two rainfalls.

Effect of sample period and target area. The effect of sample period on the number of impacts recorded varied with rainfall intensity. The number of recorded impacts reduced with increasing sample period. Differences in the total number of recorded impacts were greatest during periods of heavy rainfall because the frequency of droplets was high. During periods of light to moderate rainfall, differences due to sample period were only observed for impacts registered within the lower bins (due to the relatively high frequency of these droplets). The number of impacts over a prolonged exposure to natural rainfall (24 February to 1 March 1999, with a total rainfall of $11.5 \mathrm{~mm}$ ) for sensors set to both 1- and 5-s sample periods is shown in Figure 9.

Large differences in both total number of recorded impacts and distribution of bin number allocation were observed between sensors for which target area was varied by using shields. As with sample period, differences varied with rainfall intensity. The recorded impact numbers for a prolonged exposure to natural rainfall (23 November to 8 December 2000, with a total rainfall of $21.4 \mathrm{~mm}$ ) for sensors with 3- and 5-cm shields and no shield are shown in Figure 10. The greatest differences were observed in the number of impacts allocated to the lowest bin number, with a decrease in number of recorded impacts as the shield size decreased.

\section{DISCUSSION}

For droplets traveling at near terminal velocity in still air, the relationship between kinetic energy and splash height was very close $\left(r^{2}>0.99\right)$, suggesting that the PI sensor measures the correct variable for determination of splash height. However, no comparisons were made with the dispersal distances of spores splashed from the leaves of infected wheat plants. Previous work $(9,13$,$) has related the vertical dispersal of several plant pathogens$ to some measure of droplet force. The variables used most frequently for this purpose have been diameter $(D)$ times velocity $(V)$ and $D V^{2}$. The vertical splash dispersal from dye cups used in this study falls within the range observed for plant pathogens (30). Therefore, data from spore dispersal studies could now be reanalyzed, substituting the original terms with kinetic energy. Due to the difficulties associated with determining drop size spectrum within natural rainfall, kinetic energy provides a more practical measurement for estimating vertical spore dispersal. The resulting analysis should enable us to determine the probable accuracy to which the PI Sensor could estimate spore dispersal distances of

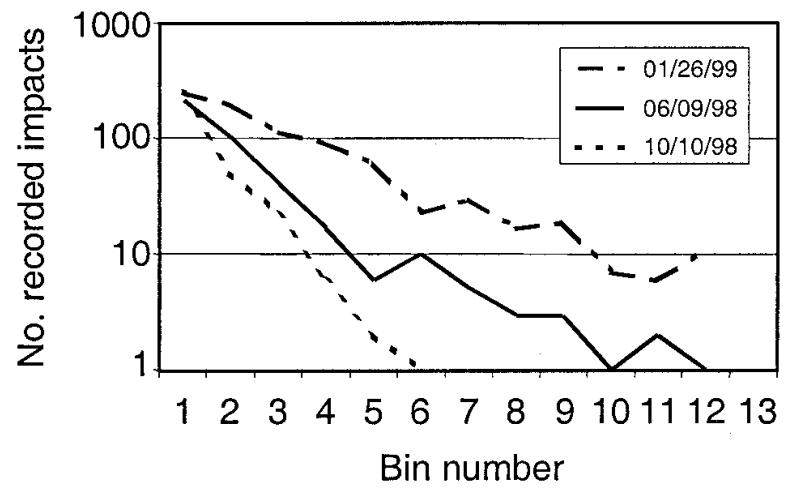

Fig. 8. Distribution of total raindrop impacts recorded by precipitation impact sensor for three distinct natural rainfall events of varying intensity and duration, at Long Ashton. pathogens studied previously. This information will enable us to assess the likely value from deployment of the PI sensor within decision support systems targeted at their control.

Data collected from the PI sensor during exposure to natural rainfall relates closely to that from the LA splashmeter. Regression analysis showed that the range of splash height for each bin number was approximately $2.5 \mathrm{~cm}$, with the minimum response at bin 1 relating to a splash height of approximately $10 \mathrm{~cm}$. Much of the variation in the data was due to the nonlinearity of the sensor's upper bins. Although this relationship could be improved by adjustment of the PI sensors offset and gain, we believe the current settings allow for the measurement of natural variation in splash height observed during spring and summer months in the United Kingdom. The current setting also covers the limits of vertical inoculum dispersal necessary to initiate infection of major pathogens such as $S$. tritici on the upper canopy leaves of U.K. winter wheat crops (11).

The PI sensor has several practical advantages over the LA splashmeter system: it is operated remotely, free of routine maintenance, is not adversely affected by wind speed or direction (i.e., for a given drop size, it will record the same bin value in both wind and still air conditions, providing the vertical velocity of droplets is unaffected), and provides both quantitative and qualitative information of rainfall events. Furthermore, the PI sensor provides a continuous measurement of rainfall, so that temporal information about rain splash can be obtained. In contrast,

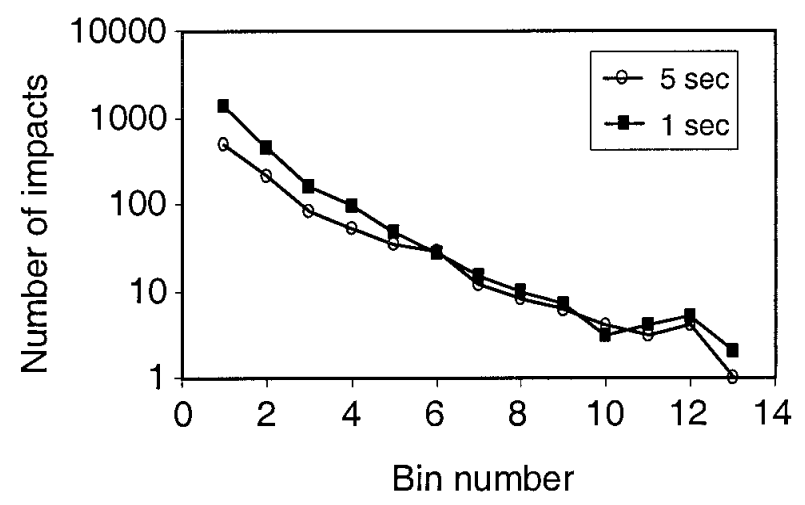

Fig. 9. Effect of precipitation impact sensor sample period on both number of recorded impacts and bin number classification for a prolonged exposure to natural rainfall totaling approximately $20 \mathrm{~mm}$ between 24 February and 1 March 1999.

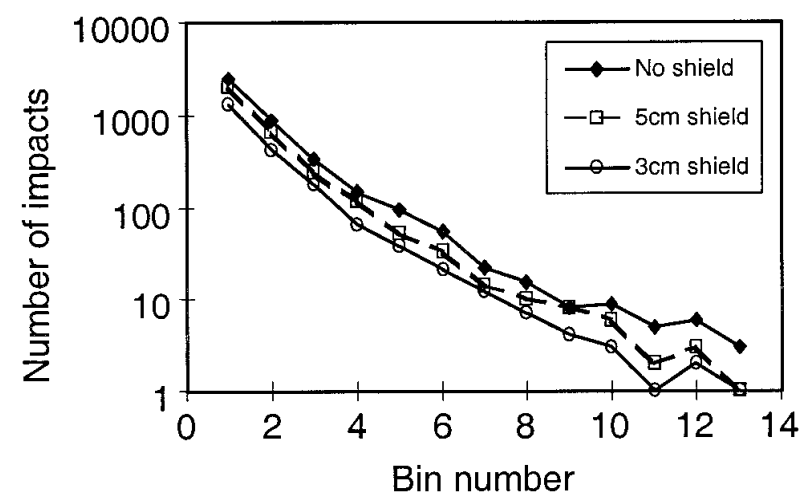

Fig. 10. Effect of precipitation impact sensor sample area, manipulated by use of aluminum shields, on both number of recorded impacts and bin number classification for a prolonged exposure to natural rainfall totaling approximately $19 \mathrm{~mm}$ between 23 November and 8 December 1998. Shield apertures were circular, with diameters of 3 and $5 \mathrm{~cm}$ providing corresponding sample areas of approximately 9 and $20 \mathrm{~cm}^{2}$. Sample area of unshielded sensor was approximately $90 \mathrm{~cm}^{2}$. 
the LA splashmeter provides a single splash value over the exposure period, regardless of whether this represents a single rainfall or multiple rainfalls of variable length. Madden et al. (15) reported a rainfall sensor that measured the accumulation of kinetic energy within defined periods. Although this device provides accurate temporal measurements of total rainfall kinetic energy, a variable that has been shown to be significantly related to total mass of reflected splash (8), estimation of splash dispersal heights from such data would most likely require information on drop size spectrum. A dual-measurement system, as described by Ulbrich $(27,28)$, could be used to provide such information. However, such methods would need to assume that the drop size spectrum was constant for the duration of the sample period. Although this may be appropriate for direct impacts of droplets at terminal velocity, a systematic underprediction is likely to occur if the sensor is used within the canopy because drips will not be at terminal velocity. The PI sensor provides a direct measurement of the kinetic energy of individual raindrop impacts. This measurement is crucial for the quantification of both maximum vertical rain splash potential and dispersal gradients. The PI sensor data can, therefore, be interpreted without reliance on complex models relating rainfall rate to the drop size spectrum. However, only the peak amplitude impact is retained for each sample period; therefore, this method compromises the accuracy of estimates of total rainfall energy, a measurement that can be used to estimate total splash dispersal volume $(6,8)$ or, for example, soil erosion or degradation of granular pesticide postapplication.

Qualitative data could be used to provide an indication of when infection of the upper canopy leaves is likely to have occurred. For example, it could answer the question of whether or not the splash height is greater than the distance between inoculum and upper canopy leaves within the crop. This mirrors the approach of the LA splashmeter system (23), but would require additional information on the spatial distribution of inoculum within the crop (12). These data could also provide crop-specific risk indices if, as suggested by Parker et al. (17), they are incorporated within a function defining the exponential decline in spore numbers with increased distance from the source. Alternatively, having identified the occurrence of conditions conducive to spore dispersal, a quantitative, presymptomatic diagnostic $(3,4)$ might be used to identify levels of infection precisely.

Quantitative data of raindrop kinetic energy (i.e., both the number and energy of impacting drops) could be used to improve the predictive accuracy of infection events through incorporation into a decision support system. Generally, such systems utilize daily rainfall totals, which can only provide crude estimates of likely spore dispersal. Recently, Pietravall et al. (18) reported a mechanistic model of splash dispersal based on the kinetic energy of individual droplets. This model provided good estimates of the dispersal of tracer dye from small crucibles (as used in the LA splashmeter). Further developments of this model should allow risk criteria for specific leaf layers or plant parts within the crop canopy. However, the model may need to account explicitly for interactions with plant surfaces, which can have a large effect on spore dispersal $(1,9,13,14,32)$. The need for such complexity will depend on the precision required for decision making, and thus may differ substantially across crop systems. For fungicide decisions on winter wheat, it may be sufficient to merely identify the potential for inoculum transport to the final three leaves, which are crucial to yield formation.

Due consideration must be given to the selection of both sample period and target or sample area when using the sensor. The most appropriate combination will be strongly influenced by how the output data is to be used. For a qualitative assessment, as in the example given earlier, the only requirement is the identification of the upper limit of droplet impaction. For this purpose, the sample period can be of indefinite length and no shield is required. Under these circumstances, low-frequency, high-energy droplets may be incorrectly recorded (underestimated) if they hit the sensor on the outer zones. However, when estimates of the maximum raindrop energy within rainfall are required, it is better to count the highenergy droplets hitting the outer zones rather than smaller droplets that fall on the central zone. For quantitative measurement or for analysis of raindrop energy spectrum, it would be desirable to have an infinitely small time period with the smallest possible sample area. This would enable precise identification of droplet kinetic energy spectrum and calculation of droplets per second per square meter. An example of how the sample period may affect quantitative analysis can be seen in a mechanistic model to predict splash dispersal and spore dispersal gradients (18). This model uses detailed information of the percentage of dye coverage on the LA splashmeter, sectioned vertically, and corresponding PI sensor data (5-s sample period). Although, in general, the model fitted well, it underestimated coverage for lower sections of the splash paper. This error may be explained by the underestimation of small droplet impacts when using a 5-s sample period. When selecting the appropriate shield-sample period combination, one needs to consider the loss of accuracy in determining impacts occurring at a distance from the center of the sensor and the frequency distribution of impacts that are of importance to record. We would suggest that a $5-\mathrm{cm}$ shield with a 1-s sample period should suffice when requiring detailed quantitative data relating to vertical spore dispersal.

The PI sensor should be of use in a range of pathosystems where rain splash is a primary cause of spore dispersal $(2,6,14)$. Validation of the relationships between sensor output and spore dispersal for these pathosystems will be provided through a dual approach of monitoring spore movements on plants in controlled environments and through the study of epidemic progress in field sown crops.

\section{ACKNOWLEDGMENTS}

This work was funded by the U.K. Ministry of Agriculture, Fisheries, and Food. We thank B. Guivarch and N. Western for technical help in the experiments, T. Hunter and A. McCartney for advice on methodologies, D. Royle and N. Paveley for continued interest and support for studies on pathogen dispersal, and D. Wingate, G. Moss (Aardware Design Ltd.), and D. Morris (AgMET) for PI sensor technical support.

\section{LITERATURE CITED}

1. Fitt, B. D. L., Inman, A. J., Lacey, M. E., and McCartney, H. A. 1992. Splash dispersal of spores of Psedocercospeorella capsellae (white leaf spot) from oilseed rape leaves of different inclination, flexibility and age. J. Plant Dis. Prot. 99:234-244.

2. Fitt, B. D. L., McCartney, H. A., and Walklate, P. J. 1989. The role of rain in dispersal of pathogen inoculum. Annu. Rev. Phytopathol. 27:241270.

3. Fraaije, B. A., Lovell, D. J., Coelho, J. M., Baldwin, S., and Holloman, D. W. 2001. PCR-based assays to assess wheat varietal resistance to blotch (Septoria tritici and Stagonospora nodorum) and rust (Puccinia striiformis and Puccinia recondita) diseases. Eur. J. Plant Pathol. 107:905-917.

4. Fraaije, B. A., Lovell, D. J., Rohel, E. A., and Hollomon, D. W. 1999. Rapid detection and diagnosis of Septoria tritici epidemics using a polymerase chain/Pico Green assay. J. Appl. Microbiol. 86:701-708.

5. Fujiwara, M. 1965. Raindrop size distribution from individual storms. J. Atmos. Sci. 22:585-591.

6. Geagea, L., Huber, L., Sache, I., Flura, D., McCartney, H. A., and Fitt, B. D. L. 2000. Influence of simulated rain on dispersal of rust spores from infected wheat seedlings. Agric. For. Meteorol. 101:53-66.

7. Hansen, J. G., Secher, B. J. M., Jorgensen, L. N., and Welling, B. 1994. Thresholds for control of Septoria spp. in winter wheat based on precipitation and growth stage. Plant Pathol. 43:183-189.

8. Huber, L., Madden, L. V., and Fitt, B. D. L. 1998. Rain-splash and spore dispersal: A physical perspective. Pages 348-370 in: Epidemiology of Plant Diseases. D. G. Jones, ed. Kluwer, Dordrecht, the Netherlands.

9. Huber, L., McCartney, H. A., and Fitt, B. D. L. 1997. Influence of target characteristics on the amount of water splashed by drops. Agric. For. Meteorol. 87:201-211. 
10. Joss, J., and Waldvogel, A. 1967. Ein Spextrograph für Niederschlagstropfen mit automatischer Auswertung. Pure Appl. Geophys. 68:240246.

11. Lovell, D. J., Parker, S. R., Hunter, T., Royle, D. J., and Coker, R. R. 1997. Influence of crop growth and canopy structure on the risk of epidemics by Mycosphaerella graminicola (Septoria tritici) in winter wheat. Plant Pathol. 47:126-138.

12. Lovell, D. J., Parker, S. R., Hunter, T., Royle, D. J., and Flind, A. C. 1997. A novel method of monitoring risk from Septoria tritici leaf blotch in winter wheat. Asp. Appl. Biol. Optimising Pestic. Appl. 48:151-154.

13. Macdonald, O. C., and McCartney, H. A. 1987. Calculation of splash droplet trajectories. Agric. For. Meteorol. 39:95-110.

14. Madden, L. V. 1997. Rainfall and the dispersal of fungal spores. Adv. Plant Pathol. 19:225-230.

15. Madden, L. V., Wilson, L. L., and Ntahimpera, N. 1998. Calibration and evaluation of an electronic sensor for rainfall kinetic energy. Phytopathology 88:950-959.

16. Parker, S. R., Lovell, D. J., Paveley, N. D., and Royle, D. J. 1997. The importance of accurate risk prediction for reliable control of Septoria leaf blotch in winter wheat. Asp. Appl. Biol. Optimising Pestic. Appl. 48:143-150.

17. Parker, S. R., Lovell, D. J., Royle, D. J., and Paveley, N. D. 1999. Analysing epidemics of Septoria tritici for improved estimates of disease risk. Pages 96-107 in: Septoria on Cereals: A Study of Pathosystems. J. A. Lucas, P. Bowyer, and H. M. Anderson, eds. CABI, Oxford.

18. Pietravall, S., van den Bosch, F., Welham, S. J., Parker, S. R., and Lovell, D. J. 2001. Modelling of rain splash trajectories and prediction of rain splash height. Agric. For. Meteorol. 109:171-185.

19. Polley, R. W., and Thomas, M. R. 1991. Surveys of diseases of winter wheat in England and Wales, 1976-1988. Ann. Appl. Biol. 119:1-20.

20. Pruppacher, H. R., and Klett, J. D. 1978. Microphysics of Clouds and Precipitation. D. Reidel, Dordrecht, the Netherlands.

21. Reynolds, K. M., Madden, L. V., Reichard, D. L., and Ellis, M. A. 1987. Methods for study of raindrop impact on plant-surfaces with application to predicting inoculum dispersal by rain. Phytopathology 77:226-232.

22. Royle, D. J., and Shaw, M. W. 1986. Recent advances towards reliable forecasting of Septoria diseases in winter wheat. Pages 207-215 in: Integr. Crop Prot. Proc. Meet. EC Experts' Group, Littlehampton, UK.

23. Shaw, M. W. 1987. Assessment of upward movement of rain splash using a fluorescent tracer method and its application to the epidemiology of cereal pathogens. Plant Pathol. 36:201-213.

24. Shaw, M. W., and Royle, D. J. 1989. Estimation and validation of a function describing the rate of yield loss in winter wheat due to infection by Mycosphaerella graminicola. Ann. Appl. Biol. 115:425-442.

25. Shaw, M. W., and Royle, D. J. 1993. Factors determining the severity of epidemics of Mycosphaerella graminicola (Septoria tritici) in winter wheat in the UK. Plant Pathol. 42:882-899.

26. Stow C. D., and Jones, K. 1981. A self-evaluating disdrometer for the measurement of raindrop size and charge at the ground. J. Appl. Meteorol. 20:1160-1176.

27. Ulbrich, C. W. 1983. Natural variations in the analytical form of the distribution of raindrop distribution. J. Clim. Appl. Meteorol. 22:17641775 .

28. Ulbrich, C. W. 1985. The effects of dropsize distribution truncation on rainfall integral parameters and empirical relations. J. Clim. Appl. Meteorol. 24:580-590.

29. Walklate, P. J. 1989. Vertical dispersal of plant pathogens by splashing. Part I: The theoretical relationship between rainfall and upward splash. Plant Pathol. 38:56-63.

30. Walklate, P. J., McCartney, H. A., and Fitt, B. D. L. 1989. Vertical dispersal of plant pathogens by splashing. Part II: Experimental study of the relationship between raindrop size and splash height. Plant Pathol. 38: 64-70.

31. Wang, P. K., and Pruppacher, H. R. 1977. Acceleration to terminal velocity of cloud and raindrops. J. Appl. Meteorol. 16:275-280.

32. Yang, X., and Madden, L. V. 1993. Effects of ground cover, rain intensity and strawberry plants on splash of simulated raindrops. Agric. For. Meteorol. 65:1-20. 